\title{
Busca de qualidade e segurança no cuidado ao filho: interações familiares com profissionais de Home Care
}

\author{
Search for quality and safety in child care: family interactions with home care professionals \\ Búsqueda de calidad y seguridad en cuidado al hijo: interacciones familiares con profesionales del \\ Home Care
}

\author{
Roberto Corrêa Leite ${ }^{1}$ (D) \\ Circéa Amalia Ribeiro² \\ Mariana Lucas da Rocha Cunha ${ }^{1}$ (1) \\ Edmara Bazoni Soares Maia² (1) \\ Luiza Watanabe Dal Ben ${ }^{3}$ (1) \\ Fabiane de Amorim Almeida ${ }^{1}$ (B)
}

1. Faculdade Israelita de Ciências da Saúde Albert Einstein. São Paulo, SP, Brasil.

2. Universidade Federal de São Paulo, Escola Paulista de Enfermagem. São Paulo, SP, Brasil.

3. Faculdade de Educação em Ciências da Saúde, Hospital Alemão Oswaldo Cruz. São Paulo, SP, Brasil.

Autor correspondente:

Roberto Corrêa Leite.

E-mail: leite.rc@uol.com.br

Recebido em 27/06/2021.

Aprovado em 15/09/2021.

\section{RESUMO}

Objetivo: compreender a vivência do cuidador familiar de crianças/adolescentes assistidos pela equipe multiprofissional em Home Care. Método: estudo qualitativo, tendo o Interacionismo Simbólico como referencial teórico, realizado com nove famílias de crianças/adolescentes em internação domiciliar, atendidas em uma empresa de Home Care localizada em São Paulo. Os dados foram coletados entre abril e outubro de 2017, por meio de entrevistas semiestruturadas, e submetidos à análise qualitativa de conteúdo convencional. Resultados: as subcategorias Vivendo em constante estado de alerta e Dando um passo à frente para garantir um cuidado seguro e qualificado evidenciaram que os familiares ressignificam o cuidado, mostrando-se alertas, no sentido de redirecionar suas ações para prover uma assistência idealizada. Conclusão: o Home Care exige dos familiares o enfrentamento de novos desafios e difíceis adaptações, além da preocupação com a segurança e qualidade do atendimento, levando-os a desenvolverem estratégias para lidar com a situação. Implicações para a prática: os discursos dos familiares sinalizam a urgência da inserção da temática do cuidado pediátrico em Home Care nas pautas de debates e discussões acadêmicas, e seu desdobramento em investimentos por parte de gestores e serviços de atendimento domiciliar, a fim de garantir uma assistência segura à criança/adolescente e sua família.

Palavras-chave: Cuidadores; Enfermagem Pediátrica; Qualidade da Assistência à Saúde; Segurança do Paciente; Serviços de Assistência Domiciliar.

\section{ABSTRACT}

Objective: to understand the experience of family caregivers of children/adolescents assisted by the multidisciplinary team in home care. Method: this is a qualitative study, with Symbolic Interactionism as a theoretical framework, carried out with nine families of children/adolescents in home care, assisted by a home care company located in São Paulo. Data were collected between April and October 2017, through semi-structured interviews, and submitted to qualitative analysis of conventional content. Results: the subcategories Living in a constant state of alert and Taking a step forward to ensure safe and qualified care showed that family members give new meaning to care, showing themselves to be alert, in the sense of redirecting their actions to provide idealized care. Conclusion: home care requires family members to face new challenges and difficult adaptations, in addition to the concern with safety and quality of care, leading them to develop strategies to deal with the situation. Implications for practice: family members' speeches signal the urgency of inserting the theme of pediatric home care in the agendas of academic debates and discussions, and its unfolding in investments by managers and home care services, in order to ensure a safe assistance to children/adolescents and their family.

Keywords: Caregivers; Pediatric Nursing; Quality of Health Care; Patient Safety; Home Assistance Services.

\section{RESUMEN}

Objetivo: comprender la experiencia de los cuidadores familiares de niños/adolescentes asistidos por el equipo multidisciplinario en Home Care. Método: estudio cualitativo, con Interaccionismo Simbólico como marco teórico, realizado con nueve familias de niños/adolescentes en atención domiciliaria, atendidos en una empresa de Home Care ubicada en São Paulo. Los datos fueron recolectados entre abril y octubre de 2017, a través de entrevistas semiestructuradas, y sometidos a análisis cualitativo de contenido convencional. Resultados: las subcategorías Vivir en constante estado de alerta y Dar un paso adelante para garantizar una atención segura y calificada mostraron que los familiares dan un nuevo significado al cuidado, mostrándose alerta, en el sentido de reorientar sus acciones para brindar un cuidado idealizado. Conclusión: Home Care requiere que los familiares enfrenten nuevos desafíos y adaptaciones difíciles, además de la preocupación por la seguridad y la calidad de la atención, lo que los lleva a desarrollar estrategias para enfrentar la situación. Implicaciones para la práctica: los discursos de los familiares señalan la urgencia de insertar el tema de la atención pediátrica en Home Care en las agendas de los debates y discusiones académicas, y su despliegue en inversiones de los administradores y de los servicios de atención domiciliaria, con el fin de garantizar la seguridad del cuidado infantil/adolescente y su familia.

Palabras clave: Cuidadores; Enfermería Pediátrica; Calidad de la Atención de Salud; Seguridad del Paciente; Servicios de Atención de Salud a Domicilio. 


\section{INTRODUÇÃO}

De modo geral, as condições de vida da população têm melhorado nos últimos anos, contribuindo significativamente para o aumento da sobrevida não só de adultos e idosos, mas também de crianças e adolescentes em cuidados complexos com a saúde. ${ }^{1}$ Nesse contexto, diante de uma doença limitante e que ameaça a vida, representada por anomalias congênitas, câncer e condições neurológicas, cada vez mais as crianças são direcionadas para o cuidado paliativo em casa. ${ }^{2}$

Tal fato também está atrelado ao avanço cientifico e inserção de novas tecnologias nos âmbitos hospitalar e nos serviços de atenção domiciliar, também conhecidos como Home Care. ${ }^{1}$

Além disto, o estímulo à desospitalização precoce segura e a preocupação com a melhor qualidade de vida de pacientes com doenças crônicas e usuários de tecnologia vêm ampliando a demanda por serviços de Home Care, o que tem impactado positivamente na redução de custos com a saúde da população.,

Destaca-se que, na saúde suplementar, o pedido para acompanhamento de um paciente por meio do Home Care depende do envio de um relatório médico à operadora de saúde. Esse documento, elaborado pelo médico assistente, detalha as condições clínicas, histórico, prescrições, exames, intercorrências e a justificativa para a alta do paciente, vinculada ao atendimento domiciliar. A partir dessa conduta, a operadora de saúde solicita avaliação para uma de suas empresas de Home Care credenciadas e aguarda o parecer da equipe de saúde com a devolutiva de um plano de atenção domiciliar. ${ }^{4}$

Vale salientar que o Home Care não é uma modalidade de atendimento regulamentado pela Agência Nacional de Saúde Suplementar, sendo considerado uma concessão aos usuários de planos privados de assistência à saúde e ainda um desafio a ser conquistado. . $^{4}$

Dessa forma, tendo em vista a importância estratégica da desospitalização, as mudanças no perfil demográfico e epidemiológico da população mundial, somada às transformações sociais e culturais, torna-se fundamental repensar sobre o modelo de atenção em saúde com destaque ao Home Care, representado pelos serviços de assistência domiciliar. ${ }^{3,6,7}$ A enfermagem representa o maior contingente de profissionais envolvidos no cuidado domiciliar, ${ }^{3}$ no entanto, diante de uma demanda crescente por esses serviços, constata-se escassez de mão de obra neste contexto.

No cenário de cuidados pediátricos, essa realidade se mostra ainda mais adversa, uma vez que a assistência à saúde direcionada para essa clientela demanda habilidades e competências específicas, sendo permeada por desafios, fragilidades físicas e emocionais que dificultam o atendimento e refletem nos relacionamentos com as famílias. ${ }^{8}$

Quando o cenário de cuidado é o domicílio, essas dificuldades se acentuam naturalmente, adicionadas aos desafios inerentes ao próprio serviço de Home Care. ${ }^{8}$ Assim, este atendimento impacta o cotidiano das famílias, ao mudar a rotina da casa e a definição de papéis, interferindo na liberdade e autonomia do sistema familiar frente à presença constante dos profissionais. Também provoca desgaste emocional e físico, insegurança e sobrecarga do cuidador, que também vivencia o próprio despreparo para o cuidado domiciliar quando redes de apoio são insuficientes e os profissionais não são qualificados. . $^{2,9,10}$

Sendo assim, a atuação de profissionais no domicílio requer competências e perfil específicos que lhes permitam oferecer uma assistência de qualidade, visto que o seu trabalho será desenvolvido na intimidade da família. ${ }^{11}$ Nesse cenário, a equipe de saúde interage com diversos arranjos familiares, constituídos por culturas, crenças e valores próprios, além de diferentes expectativas. Isso exige, por parte dos profissionais, um grande esforço a ampliar seu olhar para além do biológico e uma adequada adaptação, a fim de proporcionar a melhor experiência ao paciente e sua família. ${ }^{4,9}$

Ademais, o profissional deve ser sensibilizado a compreender que a convivência constante dos pais com a possibilidade da perda iminente do filho está entre as experiências parentais mais estressantes. Nesse processo, o cuidador familiar desenvolve algumas estratégias para lidar com a situação, como evitar aflorar suas emoções para manter a sensação iminente da perda do filho sob controle, buscar apoio e assumir o controle para providenciar os cuidados ideais ao filho, adaptando-se e aceitando as mudanças que estão em curso. ${ }^{12}$

Tudo isso reforça a necessidade do desenvolvimento profissional de competências, no sentido de apoiar e acolher a família perante a situação de ter o filho sob cuidados domiciliares, e fortalecer o vínculo entre profissional e família para obtenção de um cuidado efetivo, de qualidade e seguro. ${ }^{8}$

A Sociedade Brasileira de Enfermeiros Pediatras publicou recentemente seu posicionamento sobre as competências essenciais, inerentes aos enfermeiros que atuam em enfermagem pediátrica, ressaltando seu importante papel na recuperação, reabilitação e cuidado paliativo de crianças e adolescentes, nos diferentes níveis de complexidade, a fim de alcançar seu bem-estar e a qualidade da assistência à saúde. ${ }^{13}$

Contudo, em nossa experiência profissional, interagindo com famílias de crianças/adolescentes atendidas em Home Care, observamos uma grande preocupação da família com a segurança do paciente e a qualidade do atendimento relacionadas às questões técnicas, relacionais e do ambiente de cuidado.

Desse modo, almejando compreender melhor este cenário e não encontrando respostas na literatura, este estudo tem o objetivo de compreender a vivência do cuidador familiar de crianças/adolescentes assistidos pela equipe multiprofissional em uma empresa de Home Care.

\section{MÉTODO}

Trata-se do recorte de uma dissertação de mestrado, com abordagem qualitativa, tendo o Interacionismo Simbólico como referencial teórico. ${ }^{14}$ Para os interacionistas, a sociedade e o indivíduo estão em estreita relação, por meio de ações individuais e coletivas, sendo que os sentimentos e atitudes são construídos a partir dos significados atribuídos pelas pessoas aos objetos e símbolos. Fundamenta-se na concepção de que o ser humano age em relação ao mundo de acordo com o significado que as coisas têm para ele. ${ }^{14}$ 
Por sua vez, os significados das coisas possuem suas origens na interação social entre as pessoas e, a partir desta interação, elas aprendem a ver o mundo por meio de um processo interpretativo utilizado pelo indivíduo ao se relacionar com coisas ou objetos. ${ }^{14}$ Nessa perspectiva, o referencial permitiu ampliar a compreensão dos significados que o cuidador familiar atribui à sua interação com os profissionais de Home Care durante o cuidado da criança/adolescente em casa.

Os participantes foram selecionados por intencionalidade, ${ }^{15}$ segundo a experiência prévia do primeiro pesquisador com as famílias atendidas pelo serviço de Home Care do qual foi enfermeiro responsável. Foram estabelecidos os seguintes critérios de seleção: famílias de crianças/adolescentes com idades entre dois e 16 anos; em internação domiciliar por seis, 12 ou 24 horas, cujo cuidador familiar desempenhava essa função há mais de um ano.

A partir disso, os cuidadores familiares elegíveis foram convidados a participar do estudo por meio de contato telefônico, momento em que foram apresentados os objetivos, riscos, benefícios e como seria a participação deles na pesquisa. As entrevistas foram agendadas mediante a disponibilidade do cuidador, sendo acordado no momento do convite. Todas as famílias convidadas aceitaram participar do estudo e assinaram o Termo de Consentimento Livre e Esclarecido.

Foram entrevistados 14 cuidadores familiares de crianças/ adolescentes com doenças crônicas, pertencentes a nove famílias atendidas em uma empresa privada de Home Care localizada no interior do estado de São Paulo. De acordo com a renda financeira, os participantes pertenciam à classe média, possuíam entre 19 e 47 anos, sendo que nove eram mães, sete eram casadas, uma era divorciada e outra era separada. Apenas um era irmão da criança/adolescente e quatro eram pais que auxiliavam no cuidado. O nível escolar mínimo dos cuidadores foi o ensino médio completo, sendo que três possuíam nível superior completo, e dois, pós-graduação. Quanto à ocupação das mães que participaram da pesquisa, cinco eram do lar, uma era fonoaudióloga, uma era comerciante, uma era cobradora de pedágio e uma era gerente de recursos humanos. Já em relação aos pais, um era caldeireiro, um era engenheiro civil, um era analista de sistemas, um era mecânico e outro era ferramenteiro.

Sobre as crianças/adolescentes, nove tinham entre dois e 16 anos de idade, possuíam doenças neurológicas e malformações congênitas. Sete eram dependentes de tecnologias, como ventilador mecânico, presença de traqueostomia e gastrostomia, e encontravam-se em internação domiciliar com acompanhamento de enfermagem durante 24 horas, uma com 12 horas e outra com internação domiciliar por 6 horas. O tempo de atendimento em Home Care variou de 8 anos e 9 meses a 1 ano e 3 meses. A coleta de dados foi realizada nos domicílios, pelo primeiro pesquisador (mestrando em enfermagem), por meio de uma entrevista semiestruturada gravada em áudio, com duração média de 80 minutos, realizada entre abril e outubro de 2017.

Para favorecer a comunicação e o estabelecimento do vínculo com o cuidador, utilizou-se o genograma e ecomapa como estratégia inicial de abordagem, ressaltando-se, contudo, que esses registros não se constituíram em objetos de análise. ${ }^{16}$ Findada essa etapa, as entrevistas foram norteadas pela seguinte questão: como você percebe a atuação da equipe multiprofissional do Home Care ao lidar com seu filho?

A inclusão de novos participantes foi interrompida a partir do momento em que ocorreu a saturação teórica, ou seja, quando se percebeu que os dados obtidos já eram suficientes para permitir a compreensão do fenômeno. ${ }^{15}$

A sistemática da análise dos dados seguiu o determinado pela análise qualitativa de conteúdo convencional, que se constitui em um recurso metodológico no qual a codificação de categorias deriva diretamente dos dados empíricos. ${ }^{17}$ Sua aplicação se justifica pelo fato de fornecer informação direta dos participantes sem impor teorias ou categorias preconcebidas. Além disso, esta abordagem é apropriada quando o fenômeno a ser estudado carece de maior compreensão. Assim, após a leitura exaustiva dos dados, a análise percorreu as quatro etapas preconizadas pelo método: codificação dos dados, categorização, integração e descrição das categorias. ${ }^{17}$

O estudo foi aprovado pelo Comitê de Ética em Pesquisa, sob Parecer nำ1.906.931 e CAAE 63242316.6.0000.0071. Todos os preceitos éticos foram respeitados e para assegurar o anonimato, os fragmentos das falas dos familiares foram identificados pela função na família, pai ou mãe, seguido do número de ordem de sua entrevista.

\section{RESULTADOS}

O conteúdo expresso pelos entrevistados permitiu a construção da categoria central Buscando garantir a segurança e qualidade do cuidado ao filho em Home Care, que evidencia a constante preocupação da família em prover um cuidado seguro e qualificado ao filho. Para isso, eles ressignificam esse cuidado, mostram-se alertas e decidem redirecionar as ações em um movimento para prover o cuidado idealizado. Essa categoria se constitui por duas subcategorias: Vivendo em constante estado de alerta e Dando um passo à frente para garantir um cuidado seguro e qualificado, e serão apresentadas a seguir.

Vivendo em constante estado de alerta revela que os pais, ao interagirem com a equipe multiprofissional em domicílio, frequentemente se deparam com a inexperiência, o despreparo técnico e a falta de habilidades desses profissionais para lidar com crianças/adolescentes. Esta situação é definida por eles como um grande desafio a ser enfrentado, o que os faz viver em constante estado de alerta, gerando sobrecarga física e emocional e alterando o sentido de suas vidas. Nessa interação, a família tem a expectativa de que os profissionais são experientes no cuidado com crianças, decepcionando-se, gradativamente, ao perceberem uma postura mais voltada para o contexto hospitalar, valorizando a doença em detrimento de uma atenção voltada para as peculiaridades da família inserida no cuidado domiciliar.

Ah, os profissionais que começaram a trabalhar no Home Care; no início, a gente achava que, por ser da saúde, que os profissionais que viriam eram profissionais que 
tinham experiência, e, aí, foi se gerando um maior desafio. E qual era? Como que a gente vai fazer? Porque já tinha problema com fisio, com fono, agora chega a equipe de enfermagem... as pessoas não têm experiência. Então, a gente já não estava tendo vida! (Pai, Família 8).

Pai: Quando a gente veio com o Home Care para casa, a gente não tinha noção do que a gente ia encontrar. Mãe: Tanta desqualificação, pessoas assim que a gente vê despreparada para esse tipo de atendimento. Pai: Não tinha, (profissionais de enfermagem), digamos assim, com habilidades para lidar com um bebê (Pai e Mãe, Família 3).

As pessoas que tinham experiência eram as pessoas piores para trabalhar com a M. (criança). Demorou para gente entender isso, não é? Tem muitos que vem com um olhar muito hospitalar! (Mãe, Família 8).

Na perspectiva dos pais, a internação domiciliar é diferente da hospitalar e tem uma condição paliativa. Nesse cotidiano, emergem preocupações que vão desde a percepção de que o enfermeiro responsável se mostra distante da supervisão do cuidado domiciliar à constatação da falta de aptidão do técnico de enfermagem, levando-o a cometer erros durante o cuidado. Diante disso, os pais se questionam e se mostram inseguros em delegar a responsabilidade do cuidado do filho a um profissional despreparado.

A gente vê o Home Care como uma condição... um paliativo... um paralelo de uma internação hospitalar [...] então, muitas vezes, assim, a gente percebeu que, além do técnico não estar apto, a supervisão desse técnico é muito distante. Então, muitas vezes, ele (profissional de enfermagem) faz errado, poressa distância da supervisão dele (Pai, Familia 8)

[...] aí, como é que você fica? Como que você deixa o seu filho? Aquele que você preparou, planejou, ficou, abandonou tudo, largou profissão, largou tudo, morou cinco meses em um hospital... para vir qualquer pessoa (profissional de saúde) e fazer qualquer coisa? (Mãe, Família 3).

Outra mãe expressa frustração em relação ao desempenho dos profissionais que, na sua perspectiva, não parecem se preocupar em se desempenhar ao máximo para melhorar a qualidade de vida do filho. Isso implica preocupação com a falta de competência técnica dos profissionais, desencadeando insegurança e noites mal dormidas, exigindo um maior envolvimento da mãe no cuidado ao filho.

Eu tenho que dar o máximo de qualidade de vida para essa pessoa, naquilo que eu for fazer. Eu penso assim! Eu gostaria que todo mundo fizesse isso com o meu filho e não é isso que eu vivo. Essa preocupação é a nossa (pais), não é? Não trazer mais dificuldade para o L. (criança) e mais complicações para ele. É por isso que a gente insiste em profissionais que tenham um pouco mais de qualidade (Mãe, Família 3).

Então, assim... eu consigo descansar, mas com alguém que seja já adaptada com o E. (criança). Mas quando a pessoa é nova (profissional de enfermagem), eu acompanho. Aí, a rotina é assim... eu durmo muito pouco (Mãe, Família 2).

Eu não conhecia a equipe. Então, até eu conseguir desligar e ter uma noite tranquila, foi quase um mês. Eu tinha aqueles cochilos. Por quê? Porque eu sei que se desconectar (ventilador mecânico) e ninguém ouvir, meu filho vai morrer, não é? (Mãe, Família 5).

No entendimento de um dos pais, trabalhar no serviço de Home Care significa, para os profissionais, uma fonte de renda secundária, ou ainda uma oportunidade para adquirirem mais experiência, e, no futuro, conseguirem melhores posições no mercado de trabalho, como atuar em instituições hospitalares.

Pela experiência que a gente tem dentro da casa, todo mundo entra com o sonho de entrar no hospital. Todo mundo tem esse desejo. Éum trampolim, não é? Porque hospital não pega sem experiência... muitos profissionais encaram também como bico (o trabalho no Home Care) (Pai, Família 8).

Apesar do desgaste da família decorrente da preocupação constante com a atuação dos profissionais, existem laços afetivos que também são construídos, levando a família a sofrer com a rotatividade de profissionais no serviço de Home Care. Ademais, essa constante troca de profissionais também é percebida como desgastante para o filho e para a própria empresa de Home Care.

Mãe: Um dos pontos também que, assim, que é muito desgastante, tanto para nós quanto para eles (profissionais de enfermagem), acredito que para o Home Care também e para M. (criança) principalmente, é a troca. Pai: Sabe, a gente sabe que ela (profissional de enfermagem) vai arrumar emprego e aí, a gente vai sofrer. Quem sofre? Somos nós... (Mãe e Pai, Família 8).

Uma das mães relata que os profissionais que atuam área administrativa do Home Care, no caso o enfermeiro, mostramse indiferentes ao cuidado do seu filho.

Aqui, (a atuação dos profissionais em casa) para mim, é ótimo. Parece assim: eles (enfermeiros que atuam na área administrativa do Home Care) não estão aqui dentro, então... tanto fez, tanto faz. [...] então, para mim, o meu lado positivo são os profissionais dentro da minha casa, o tratamento com a minha filha e o lado negativo é o lado de fora (área administrativa) (Mãe, Família 6). 
A subcategoria Dando um passo à frente para garantir um cuidado seguro e qualificado revela que, a partir da insegurança dos cuidadores diante do despreparo técnico da equipe multiprofissional, com destaque para os profissionais de enfermagem, os familiares se mobilizam na busca de conhecimento, que até então não possuíam, esforçando-se para aprender com os profissionais mais experientes a melhor maneira de cuidar do filho.

E agora? (despreparo técnico da equipe) A gente está com enfermagem, o que a gente vai ter que fazer? Vai ter que treinar. Mas a gente não tem conhecimento suficiente, eu não sei. Então, o que a gente foi fazer? A gente foi tentar é.... aprender. Então, nós tínhamos uma das técnicas, que já trabalhava na UTI do hospital... Ela se propôs a trabalhar em casa. Foi bem no começo [...] como o hospital intensificava bastante o treinamento, ela nos ajudou bastante (Pai, Família 8).

Ah! Então, elas (profissionais de enfermagem) me treinaram no hospital. Sabe? Elas falavam: vamos treinar você porque vai precisar fazer isso lá na sua casa [...] sabe, eu pensava, não vou conseguir, não vou conseguir, mas consegui! (Mãe, Família 9).

Assim, diante desta condição de insegurança, os pais se percebem na obrigação de buscar o conhecimento e ensinar o profissional de Home Care a cuidar da criança/adolescente em internação domiciliar.

Eu tive que eu ensinar... assim... não tem problema nenhum de eu ensinar, [...]. Mas o básico que é aspirar (traqueostomia), o Home Care tem que mandar gente que saiba aspirar, sendo que, quando a menina (profissional de enfermagem) veio, essa que a gente ficou, ela veio no dia que eu ia trabalhar. Eu falei: não, eu não vou, eu tenho que esperar! Eu cheguei atrasada, aquele dia, no serviço... (Mãe, Família 5).

Então, a gente teve que conhecer como que funciona todas as medicações dela. É, e a gente tem as medicações controladas que é o: se necessário! As controladas, nós isolamos do quarto. Por quê? As meninas (técnicas de enfermagem) misturam [...] ninguém administra $o$ Diazepan nela, a não ser a gente (pais) (Pai, Família 8).

Nesse sentido, buscando garantir a qualidade técnica dos atendimentos, os familiares se empenham para defender a permanência, o maior tempo possível, dos mesmos profissionais de enfermagem na escala de serviço, amenizando o impacto da adaptação da criança e da família ao novo colaborador.

Eu até briguei para manter as meninas (profissionais de enfermagem) que já cuidavam dele (criança), que já estavam acostumadas. Acho que não é nem saudável para ele (criança) e nem para ninguém, ficar com esse monte de troca (rotatividade na escala de enfermagem) também (Mãe, Família 5).

$\mathrm{Na}$ tentativa de dar um passo à frente para garantir a segurança do filho, a mãe decide entrevistar o profissional recém-admitido no serviço domiciliar antes de começar a atuar em sua casa, buscando conhecer melhor o seu perfil e se corresponde às expectativas da família.

Eu faço entrevista quando há necessidade de uma técnica (profissional de enfermagem), e, se eu vejo que a pessoa é muito fora do perfil da equipe toda do Home Care... da equipe daqui, da enfermagem...médico, fisioterapeuta... eu já peço para não vir (Mãe, Família 2).

Enfim, embora os familiares reconheçam que o cuidado em Home Care não é uma tarefa fácil, eles destacam a importância da conquista e do estabelecimento de confiança mútua com a equipe multiprofissional.

Então, não é fácil. Você precisa ter uma boa equipe... você precisa ganhar a confiança delas (das profissionais

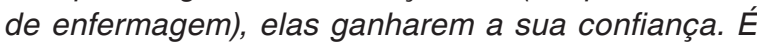
tudo... tudo um conjunto. [...] mas que também possam gerar confiança para a família inteira! (Mãe, Família 1).

\section{DISCUSSÃO}

Dentre os achados do estudo, a busca pela segurança do paciente e qualidade da assistência à saúde são aspectos que marcam o dia a dia da família com o filho em cuidados de Home Care. A interação é permeada por preocupações com as falhas na qualidade de entrega dos atendimentos, caracterizada pela ausência de um adequado fluxo de troca de informações entre a equipe que atua no Home Care e os cuidadores familiares, além de fragilidades evidenciadas em relação às competências e habilidades na área administrativa deste sistema.

Vivendo em constante estado de alerta emerge diante do reconhecimento das vulnerabilidades técnicas pela família, que são significadas na interação com a equipe multiprofissional. Assim, os membros desta família se sentem obrigados a assumir o protagonismo na assistência aos filhos. Nota-se a responsabilidade e preocupação do cuidador familiar consigo e com o outro, ${ }^{14}$ representado nesse cenário pela criança/adolescente. Essa seria uma ação esperada no atendimento em Home Care, para que esse cuidador pudesse ser, progressivamente, o protagonista do cuidado aos seus filhos. Entretanto, esse protagonismo não pode se impor em função do despreparo técnico e relacional de quem, por excelência, deveria fornecer qualidade e segurança no atendimento.

Estudos enfatizam a necessidade de capacitação dos profissionais, a fim de garantir a transição segura entre 0 cuidado hospitalar e domiciliar, respeitando-se todas as suas peculiaridades, sobretudo no cuidado de crianças com condições complexas. Ressaltam, ainda, que o conhecimento 
contribui para o empoderamento destes profissionais, o que provavelmente os tornaria melhor qualificados para exercer esta atividade e traria maior segurança às famílias., ${ }^{7,18}$

Uma pesquisa, realizada com foco na visão dos profissionais que atuam no serviço de Home Care, aponta que a manutenção de elevados índices de satisfação dos familiares e pacientes está estreitamente relacionada ao investimento em programas de capacitação para esses profissionais antes de começarem a atuar nos domicílios. ${ }^{19}$

Contudo, no contexto de cuidado domiciliar, esse "empoderamento" sofre influências da produção e troca de conhecimentos envoltos em significados que direcionam as ações dos cuidadores e da equipe multiprofissional, sendo resultado das interações com as rotinas próprias de cada domicílio e a vivência dentro de um espaço privado que não pertence a todos os envolvidos. ${ }^{20} \mathrm{E}$ é por essa característica do cuidado domiciliar que os currículos de formação devem possibilitar o desenvolvimento de competências e de uma ética que considere a complexidade e a especificidade da assistência em domicílios. ${ }^{9}$

Logo, a formação para atuar em serviços de assistência domiciliar deve considerar, além do domínio dos procedimentos técnicos especializados, a multiplicidade das dinâmicas familiares e a capacidade dos profissionais em incorporar os valores, saberes e as potencialidades da família por meio de apoio, estabelecimento de vínculo e o desenvolvimento de habilidades e competências específicas para este cuidado. ${ }^{9,21}$ Tal fato não foi observado neste estudo quando a família buscou se fortalecer por iniciativa própria para proteger o filho, apoiando-se nos profissionais com expertise hospitalar.

Entretanto, no presente estudo, tensões se mostram entre os profissionais com pouca experiência e inabilidade técnica, e os profissionais que possuem experiência hospitalar, permeados pela falta de confiança e vínculo no trabalho de ambos. Assim, mesmo os profissionais com experiência não atenderam às expectativas dos familiares no cuidado ao filho, devido à sua visão hospitalar. Possivelmente, essa percepção dos cuidadores é influenciada pela primazia acadêmica do modelo biomédico, em detrimento de uma prática centrada no paciente e família, o que restringe o olhar do profissional apenas à pessoa doente, afetando a confiança e o vínculo. ${ }^{22}$

Ainda sobre esse aspecto, destaca-se a importância de o enfermeiro aprender, em sua formação, sobre a implementação da tecnologia leve na abordagem familia-. Sua aplicação envolve interações humanas, por meio da escuta ativa, que também favorece o vínculo e a confiança entre os pacientes, famílias e profissionais. Por ser tão abrangente e utilizada na aplicação das demais tecnologias, a tecnologia leve constitui-se no maior desafio para a formação dos enfermeiros que atuam em Home Care. ${ }^{11}$

O enfermeiro tem um lugar fundamental na gestão do cuidado domiciliar, auxiliando as famílias a se organizarem frente às dificuldades. ${ }^{9}$ No entanto, estudo qualitativo revelou que a falta de habilidade dos enfermeiros para cuidar de crianças em casa é algo comum na rotina das famílias, contribuindo para o aumento das internações hospitalares, procedimentos médicos e sobrecarga dos cuidadores, que não encontraram no enfermeiro um ponto de apoio para cuidar de seus filhos. ${ }^{23}$ Dado similar foi ressaltado neste estudo pelos pais, ao referirem a ausência do enfermeiro na supervisão direta do cuidado domiciliar.

O atendimento no domicílio é reconhecido pelo usuário como a melhor opção de assistência ao cliente com doenças crônicas ou dependente de tecnologias, propiciando-lhe o conforto do lar e favorecendo o vínculo com a família e com a equipe, além de superar as barreiras de acesso a outros pontos da rede de atenção à saúde. Na perspectiva dos usuários, o cuidado em casa apresenta novas relações que ampliam o acesso, a autonomia e a qualidade de vida dos pacientes. ${ }^{24}$ No presente estudo, a falta de envolvimento do profissional de saúde em promover a autonomia e valorizar a qualidade de vida dos pacientes em direção à reabilitação também foram motivos de insatisfação por parte do cuidador familiar, além das fragilidades técnicas.

Adicionalmente, para que haja satisfação do cuidador familiar e a adequada evolução clínica do paciente atendido em domicílio, é necessário que as relações entre família e profissionais estejam em equilíbrio, pois ambos precisam do apoio uns dos outros. ${ }^{25}$ Dessa forma, a família deve contribuir ativamente e ser envolvida nas definições das ações praticadas no domicílio.

Sob essa ótica, é necessário que os profissionais de saúde desenvolvam planos terapêuticos a partir de metas que estejam em consonância com as expectativas dos usuários, a rotina e dinâmica familiar, e recursos disponíveis. Por conseguinte, levando em consideração a capacidade e o potencial do paciente e do cuidador familiar no alcance dos objetivos, fundamentado em decisões consensuais entre os profissionais de saúde, pacientes e cuidadores. ${ }^{26}$

Espera-se que, dessa forma, seja possível promover uma adequada reabilitação do paciente no âmbito domiciliar, visando sua autonomia de acordo com seus limites e esperanças da família em direção à integralidade da assistência e melhora na qualidade de vida. ${ }^{26}$

Revisão de literatura verificou que, em geral, no âmbito do Sistema Único de Saúde, as famílias sentem-se satisfeitas com o serviço prestado pelas equipes de assistência domiciliar, contudo apontam que tal avaliação pode estar ligada a sentimentos de gratidão pelo caráter público e gratuito e não pelo entendimento de saúde como direito, dificultando a expressão de críticas e insatisfação com o serviço prestado. ${ }^{9}$ Neste estudo, que foi desenvolvido no âmbito de atenção à saúde privado, as famílias se mostraram potentes na avaliação e no reconhecimento das fragilidades técnicas e relacionais da equipe.

Os resultados apontam que a rotatividade dos profissionais de enfermagem foi uma questão relevante e destacada pela família como motivo de insatisfação. De modo geral, no cenário de atendimento domiciliar privado, os pacientes são assistidos por profissionais autônomos ou provenientes de uma cooperativa de trabalho. Nessa prática, observa-se que o tempo de permanência do profissional na residência é dependente da sua capacidade de adaptação e da boa interação que 
ele estabelece com o paciente e a família, bem como pelas condições clínicas apresentadas pelo cliente.

Assim, não é possível prever com exatidão se haverá adaptação do profissional em uma determinada residência, uma vez que, no sistema privado, a família e o paciente podem escolher os profissionais que trabalharão em sua casa. A preocupação com a rotatividade dos profissionais também foi relatada em outro estudo realizado no Programa Melhor em Casa, apontado como risco à qualidade da assistência, devido ao rompimento de vínculo com os usuários e interferência na condução do plano terapêutico. ${ }^{25}$

Nesse contexto, a literatura também evidencia a relevância em perguntar ao cliente o que ele acredita ser mais importante na assistência prestada. Essa iniciativa possibilita maior flexibilidade no plano de cuidados ao considerar as necessidades dele, entendendo estar ele na melhor posição para saber quais são as suas preferências. ${ }^{27}$

No entanto, constatou-se que a família se mobiliza, Dando um passo à frente para garantir um cuidado seguro e qualificado ao filho, em decorrência da insegurança com a atuação da equipe e com a falta de liderança e supervisão do enfermeiro, decidindo assumir esse papel. Desse modo, perante as situações de estresse vivenciadas, os cuidadores desenvolveram estratégias para se adaptarem e readaptarem à nova realidade de cuidar da criança/adolescente em casa, as quais influenciaram no funcionamento da família e na manutenção do bem-estar. Evidencia-se aqui a primeira premissa do Interacionismo Simbólico, na qual a forma de agir do indivíduo depende do significado que as coisas possuem para ele: ${ }^{14}$ cuidar do filho com qualidade e segurança.

Nesse sentido, querer aprender sobre o cuidado profissional, dentre outras estratégias citadas neste estudo, fazem parte deste processo de adaptação das famílias, que ocorre à medida em que os cuidadores recebem informações e são orientados pela equipe multiprofissional. ${ }^{28}$ Sobre este aspecto, a literatura destaca o hibridismo entre o fazer profissional e o familiar, acarretado pela interferência mútua destas lógicas, a partir das interpretações de aspectos simbólicos entre os sujeitos perante o cotidiano do Home Care. ${ }^{20}$

De acordo com Interacionismo Simbólico, a capacidade do ser humano de se antever a um evento futuro é alcançado quando o mesmo se coloca no lugar do outro. ${ }^{14}$ Considerando, neste estudo, o outro simbolizado pela criança/adolescente, os cuidadores familiares interagind o com a equipe de enfermagem, tecnicamente debilitada, adquiriram habilidades para antecipar quais seriam as reações do outro e, a partir disso, desenvolveram estratégias para que pudessem aprender sobre o cuidado, provendo apoio e proteção aos seus filhos.

Frente ao contexto da fragilidade técnica vivenciada pelos cuidadores familiares na assistência aos seus filhos, cabe ressaltar a importância dos profissionais de saúde, em especial o enfermeiro, em prepará-los, ainda durante a internação hospitalar, em relação à autonomia para a execução de cuidados complexos em domicílio, focados nas condições clínicas, nutricionais, sociais e uso de tecnologias e medicamentos. ${ }^{29}$
Na prática, observa-se que o processo de educação e preparação do cuidador familiar para a alta ainda é algo incipiente, não segue normas e padrões definidos entre os membros da equipe multiprofissional, resultando em insegurança para os familiares assumirem o cuidado no domicílio. A esse respeito, ressalta-se a responsabilidade do hospital em garantir que o cuidador familiar seja orientado antes da alta quanto à continuidade do tratamento domiciliar, reforçando a sua autonomia enquanto protagonista do cuidado. ${ }^{30,31} \mathrm{~A}$ partir disso, os cuidadores estariam melhor preparados para manejar a falta de capacitação técnica da equipe e as vicissitudes que estarão por vir após o processo de desospitalização de seus filhos.

Por fim, frente à demanda crescente de pacientes dependentes do atendimento domiciliar, assinala-se a necessidade premente de reestruturação dos programas educacionais em enfermagem, com vistas a fornecer um melhor preparo aos profissionais em formação e a otimização de acesso às práticas pautadas em evidências científicas. . $^{71}$

Além disso, é necessário repensar as políticas de saúde voltadas para o Home Care em direção à regulamentação plena do setor no Brasil. Na práxis, no sistema de saúde suplementar, o seu acesso ainda não é equânime a toda população, uma vez que esse procedimento não está previsto no rol da Agência Nacional de Saúde Suplementar. Sob esse aspecto, não existe obrigatoriedade da operadora de plano de saúde em fornecer essa assistência aos seus usuários. ${ }^{4,5}$

Assim, nem sempre pacientes com as mesmas necessidades de cuidados clínicos terão autorização para esse benefício, tendo que recorrer a uma possível judicialização. Diante de tantas incertezas, surgem nessa relação as disparidades, as exceções e a falta de padronização de condutas relacionadas a autorização do atendimento domiciliar, e que refletem no cotidiano da qualidade assistencial. ${ }^{4,5}$

\section{CONCLUSÕES E IMPLICAÇÕES PARA A PRÁTICA}

Este estudo revela que o Home Care exige, por parte dos cuidadores familiares, o enfrentamento de novos desafios e difíceis adaptações, bem como o desenvolvimento de estratégias para lidar com a situação. Evidencia-se a preocupação dos familiares com a segurança e qualidade da assistência à saúde prestada à criança/adolescente, a fim de prevenir a ocorrência de iatrogenias, em função da rotatividade e da falta de qualificação dos profissionais que atuam no domicílio.

Considerando a singularidade do cuidado domiciliar presente no contexto da enfermagem pediátrica, os discursos dos familiares sinalizam a urgência de que a temática do cuidado em Home Care oferecido pela enfermagem entre nas pautas de debates e discussões acadêmicas, e se desdobrem em investimentos por parte de gestores e serviços de atendimento domiciliar, em programas de formação profissional específicos para a assistência à criança/adolescente e sua família.

Ademais, diante de uma realidade com tantas particularidades, como o Home Care, reitera-se a necessidade do enfermeiro assumir seu papel de gestor do cuidado, integrando todos 
os profissionais no planejamento do atendimento domiciliar, em ações que forneçam suporte, qualidade e segurança no cotidiano assistencial dessas famílias.

A limitação do estudo se apresentou em uma amostra composta por cuidadores de um mesmo serviço de Home Care, o que pode ter influenciado nos resultados obtidos, devido às características culturais e organizacionais da empresa. Recomenda-se o desenvolvimento de novos estudos envolvendo a perspectiva da equipe multiprofissional sobre o tema, a fim de ampliar a compreensão das condições de trabalho, como os gestores lidam com a inexperiência da equipe e sobretudo, como é para o profissional assumir esse papel e estar nessa posição.

\section{CONTRIBUIÇÕES DOS AUTORES}

Desenho do estudo. Roberto Corrêa Leite. Fabiane de Amorim Almeida. Circéa Amalia Ribeiro.

Coleta ou produção dos dados. Roberto Corrêa Leite.

Análise de dados. Roberto Corrêa Leite. Fabiane de Amorim Almeida. Edmara Bazoni Soares Maia. Circéa Amalia Ribeiro. Mariana Lucas da Rocha Cunha.

Interpretação dos resultados. Roberto Corrêa Leite. Fabiane de Amorim Almeida. Edmara Bazoni Soares Maia. Circéa Amalia Ribeiro. Mariana Lucas da Rocha Cunha.

Redação e revisão crítica do manuscrito. Roberto Corrêa Leite. Fabiane de Amorim Almeida Edmara Bazoni Soares Maia. Circéa Amalia Ribeiro. Mariana Lucas da Rocha Cunha. Luiza Watanabe Dal Ben.

Aprovação da versão final do artigo. Roberto Corrêa Leite. Fabiane de Amorim Almeida. Edmara Bazoni Soares Maia. Circéa Amalia Ribeiro. Mariana Lucas da Rocha Cunha. Luiza Watanabe Dal Ben.

\section{EDITOR ASSOCIADO}

Aline Cristiane Cavachilli Okido ()

\section{EDITOR CIENTÍFICO}

Ivone Evangelista Cabral (1)

\section{REFERÊNCIAS}

1. Rajão FL, Martins M. Home Care in Brazil: an exploratory study on the construction process and service use in the Brazilian Health System. Cien Saude Colet. 2020;25(5):1863-77. http://dx.doi.org/10.1590/141 381232020255.34692019. PMid:32402051.

2. Winger A, Kvarme LG, Loyland B, Kristiansen C, Helseth S, Ravn $\mathrm{IH}$. Family experiences with palliative care for children at home: a systematic literature review. BMC Palliat Care. 2020;19(1):165. http:// dx.doi.org/10.1186/s12904-020-00672-4. PMid:33099303.

3. Ministério da Saúde (BR). Atenção domiciliar no SUS: resultados do laboratório de inovação em atenção domiciliar/Ministério da Saúde. Organização Pan-Americana da Saúde. Brasília (DF): Ministério da Saúde; 2014

4. Ribeiro C. Atenção Domiciliar: princípios, práticas e perspectivas. São Paulo: Eureka; 2019.

5. Resolução Normativa (RN) n. 465, de 24 de fevereiro de 2021 (BR). Atualiza o Rol de Procedimentos e Eventos em Saúde que estabelece a cobertura assistencial obrigatória a ser garantida nos planos privados de assistência à saúde contratados a partir de 1ํ de janeiro de $1999 \mathrm{e}$ naqueles adaptados conforme previsto no artigo 35 da Lei n. 99.656 , de 3 de junho de 1998. Diário Oficial da União, Brasília (DF), 2 mar 2021.

6. Braga PP, Sena RR, Seixas CT, de Castro EAB, Andrade AM, Silva YC. Supply and demand in home health care. Ciênc Saúde colet. 2016;21(3):903-12. http://dx.doi.org/10.1590/1413-81232015213.11382015.

7. Jarrín OF, Pouladi FA, Madigan EA. International priorities for home care education, research, practice, and management: qualitative content analysis. Nurse Educ Today. 2019;73:83-7. http://dx.doi. org/10.1016/j.nedt.2018.11.020.

8. Machado AN, Nóbrega VMD, Silva MEA, França DBL, Reichert APDS Collet N. Chronic disease in children and adolescents: professionalfamily bond for the promotion of social support. Rev Gaúcha Enferm. 2018;39:e20170290. http://dx.doi.org/10.1590/1983-1447.2018.20170290. PMid:30088608.

9. Procópio LCR, Seixas CT, Avellar RS, Silva KL, Santos MLM. A atenção domiciliar no âmbito do Sistema Único de Saúde: desafios e potencialidades. Saúde em Debate. 2019 abr/jun;43(121):592-604. http://dx.doi.org/10.1590/0103-1104201912123.

10. Dias BC, Ichisato SMT, Marchetti MA, Neves ET, Higarashi IH, Marcon SS. Challenges of family caregivers of children with special needs of multiple, complex and continuing care at home. Esc Anna Nery. 2019;23(1):e20180127. http://dx.doi.org/10.1590/2177-9465ean-2018-0127.

11. Andrade AM, Silva KL, Seixas CT, Braga PP. Atuação do enfermeiro na atenção domiciliar: uma revisão integrativa da literatura. Rev Bras Enferm. $2017 \mathrm{fev} ; 70(1): 210-9$. http://dx.doi.org/10.1590/0034-71672016-0214. PMid:28226061.

12. Verberne LM, Kars MC, Schouten-van Meeteren AYN, van den Bergh EMM, Bosman DK, Colenbrander DA et al. Parental experiences and coping strategies when caring for a child receiving paediatric palliative care: a qualitative study. Eur J Pediatr. 2019;178(7):1075-85. http:// dx.doi.org/10.1007/s00431-019-03393-w. PMid:31104108.

13. Gaiva MAM, Silveira A, Viera CS, Maia EBS, Anders JC, Miranda JOF et al. Posição da Sociedade Brasileira de Enfermeiros Pediatras sobre as competências essenciais do enfermeiro neonatologista $e$ pediatra. Rev Soc Bras Enferm Ped. 2020;20(2):116-33. http://dx.doi. org/10.31508/1676-3793202000016.

14. Charon JM. Symbolic interactionism: an introduction, an interpretation, an integration. New Jersey (US): Prentice Hall; 2004.

15. Hennink MM, Kaiser BN, Weber MB. What influences saturation? Estimating sample sizes in focus group research. Qual Health Res. 2019;29(10):1483-96. http://dx.doi.org/10.1177/1049732318821692.

16. Yorinobu AC, Andrade PR, Cruz AC, Silva L, Costa P, Belela-Anacleto AS. Contributions of genogram and ecomap in nursing consultations in child care. Rev Soc Bras Enferm Ped. 2019;19(1):16-22.

17. Hsieh HF, Shannon SE. Three approaches to qualitative content analysis. Qual Health Res. 2005;15(9):1277-88. http://dx.doi. org/10.1177/1049732305276687. PMid:16204405.

18. Moreira MCN, Albernaz LV, Sá MRC, Correia RF, Tanabe RF. Recomendações para uma linha de cuidados para crianças e adolescentes com condições crônicas complexas de saúde. Cad Saude Publica. 2017;33(11):e00189516. http://dx.doi.org/10.1590/0102311x00189516. PMid:29166490.

19. Alia A, Al-Salem A, Al-Ghunaim L, Al-Amri S. The quality of home healthcare service in Riyadh/Saudi Arabia. Asian Journal of Natural \& Applied Sciences. 2016;5(2):72-81.

20. Borges MV, Silva ARL, Souza EM, Fantinel LD. Implicações simbólicas na organização de um home care: interpretações entre a equipe de saúde e os cuidadores familiares. REAd (Porto Alegre). 2016;22(1):5276. http://dx.doi.org/10.1590/1413-2311.102014.53644.

21. Dias BC, Marcon SS, Reis PD, Lino IGT, Okido ACC, Ichisato SMT et al. Family dynamics and social network of families of children with special needs for complex/continuous cares. Rev Gaúcha Enferm. 2020;41:e20190178. http://dx.doi.org/10.1590/1983-1447.2020.20190178. PMid:32491146. 
22. Carvalho NR, Andrade e Silva E, Moura de Oliveira D, Silva Cardoso Estevão A, Vieira Toledo L, Borges Figueiredo J. Percepções e práticas do técnico de enfermagem sobre a visita domiciliar na atenção primária. Rev Enf UFJF. 2019;5(1):1-17. http://dx.doi.org/10.34019/24465739.2019.v5.26768.

23. Mai K, Davis RK, Hamilton S, Robertson-James C, Calaman S, Turchi RM. Identifying caregiver needs for children with a tracheostomy living at home. Clin Pediatr (Phila). 2020;59(13):1169-1181. http://dx.doi. org/10.1177/0009922820941209. PMid:32672065.

24. Falkson S, Knecht C, Hellmers C, Metzing S. The perspective of families with a ventilator-dependent child at home. A Literature Review. J Pediatr Nurs. 2017;36:213-24. http://dx.doi.org/10.1016/j. pedn.2017.06.021.

25. Castro EAB, Leone DRR, Santos CM, Neta FCCG, Gonçalves JRL, Contim D et al. Organização da atenção domiciliar com o Programa Melhor em Casa. Rev Gaúcha Enferm. 2018;39:e2016-0002. http:// dx.doi.org/10.1590/1983-1447.2018.2016-0002.

26. Dias JF, Grossi JB, Costa LA, Furtado SRC, Mancini MC, Sampaio RF. Atenção domiciliar no âmbito da reabilitação e prática centrada na família: aproximando teorias para potencializar resultados. Rev
Ter Ocup Univ São Paulo. 2017 out;28(2):206-13. http://dx.doi. org/10.11606/issn.2238-6149.v28i2p206-213.

27. Wojtak A, Klopp J. Changing the conversation with home care clients. Healthc Q. 2015;18(3):23-7. http://dx.doi.org/10.12927/hcq.2015.24435.

28. Mendes AP. Uncertainty in critical illness and the unexpected: important mediators in the process of nurse-family communication. Esc Anna Nery Rev Enferm. 2020;24(1):e20190056. http://dx.doi. org/10.1590/2177-9465-ean-2019-0056.

29. Precce ML, Moraes JRMM, Pacheco STA, Silva LF, Conceição DS Rodrigues EC. Educational demands of family members of children with special health care needs in the transition from hospital to home. Rev Bras Enferm. 2020;73(Suppl 4):e20190156. http://dx.doi. org/10.1590/0034-7167-2019-0156. PMid:32756741.

30. Silva KL, Sena RR, Castro WS. A desospitalização em um hospital público geral de Minas Gerais: desafios e possibilidades. Rev Gaúcha Enferm. 2018;38(4):e67762. http://dx.doi.org/10.1590/19831447.2017.04.67762. PMid:29933425.

31. Góes FGB, Cabral IE. Discourses on discharge care for children with special healthcare needs. Rev Bras Enferm. 2017;70(1):154-71. http:// dx.doi.org/10.1590/0034-7167-2016-0248. PMid:28226056. 